\title{
Determination of Rheological Properties and Dispersion Quality of Shear Thickening Fluid
}

\author{
Cenk Yanen ${ }^{1}$, Murat Yavuz Solmaz ${ }^{2}$, Ercan Aydoğmuş ${ }^{3 *}$ \\ ${ }^{1}$ Frrat University, Faculty of Engineering, Departmant of Mechanical Engineering, Elazığ, Turkey, (ORCID: 0000-0002-5092-8734), cyanen@firat.edu.tr \\ ${ }^{2}$ Firat University, Faculty of Engineering, Departmant of Mechanical Engineering, Elazı̆̆, Turkey, (ORCID: 0000-0001-6394-0313), mysolmaz@firat.edu.tr \\ $3^{*}$ Firat University, Faculty of Engineering, Departmant of Chemical Engineering, Elazığ, Turkey, (ORCID: 0000-0002-1643-2487), ercanaydogmus@firat.edu.tr
}

(1st International Conference on Applied Engineering and Natural Sciences ICAENS 2021, November 1-3, 2021)

(DOI: 10.31590/ejosat.1011245)

ATIF/REFERENCE: Yanen, C., Solmaz, M.Y. \& Aydoğmuş, E. (2021). Determination of Rheological Properties and Dispersion Quality of Shear Thickening Fluid. European Journal of Science and Technology, (28), 781-784.

\begin{abstract}
In this research, the rheological properties of non-Newtonian shear thickening fluid (STF) composed of nano-sized solid particles have been investigated. The best conditions have been determined by optimizing both the experimental production method and the rheological measurement system of STFs. Mechanical, ultrasonic, and both mechanical and ultrasonic mixing methods were used in the production of STFs that nano-sized silica particle (solid: aerosil) and polyethylene glycol (liquid medium: PEG). Also, the spacing between the plates was changed during the rheological measurements and the effect on the rheological character of the suspension was also compared. Although the best homogenization was obtained with the ultrasonic mixer in the produced STFs, the lowest performance was observed in the rheological measurements of these samples. In STFs obtained at high mixing speed with a mechanical mixer, the viscosity of the fluid increased abruptly with increasing shear rate. In the measurements, it was observed that the gap change between the parallel plates did not affect the rheological characteristics much.
\end{abstract}

Keywords: Shear thickening fluid, Aerosil, Polyethylene glycol, Rheology, Optimization.

\section{Kayma Altında Katılaşan Sıvıların Reolojik Özelliklerinin ve Dispersiyon Kalitesinin Belirlenmesi}

$\ddot{O} \mathbf{z}$

Kayma altında katılaşan sıvılar (KAKS), sıvı ortamda dağıtılmış nano boyutlu katı partiküllerden oluşan Newtonyan olmayan özel bir akışkan çeşididir. KAKS'ların viskozitesinde artan kayma hızı ile birlikte ani bir artış görülür, sahip oldukları bu özellik tersinirdir ve viskoziteyi artıran gerilim ortadan kalktığında viskoziteleri ilk hallerine geri döner. KAKS'ların üretimi için katı ortam olarak kullanılan silika partiküller polietilen içerisinde üç farklı yöntem kullanılarak dağıtılmış ve üretim yönteminin dispersiyon kalitesine ve reolojik özelliklere olan etkisi incelenmiştir. Reolojik ölçümler sırasında plakalar arasındaki boşluk da değiştirilmiş ve süspansiyonun reolojik karakterine olan etkisi gözlenmiştir. Yapılan incelemelerde dispersiyon kalitesi en yüksek numunelerin ultrasonik karıştırıcı kullanılarak yapılanlar olduğu ancak reolojik özellikleri negatif etkilediği tespit edilmiştir. Reolojik ölçümlerde paralel plakalar arasındaki boşluk değişiminin grafik karakteristiğine etki etmediği gözlenmiştir.

Anahtar Kelimeler: Kayma altında katılaşan sıvı, Aerosil, Polietilen glikol, Optimizasyon. 


\section{Introduction}

Shear thickening fluids (STFs) are non-Newtonian suspensions that exhibit a sudden increase in viscosity with increasing shear rate. This property of STFs is reversible, and when the tension that increases the viscosity is removed, the liquids can return to their original state. A lot of research has been done to understand the rheological properties of these fluids and to use them in engineering applications. To understand the solidification mechanisms of STFs, in Hoffman's study, it was stated that before the critical shear stress, the solid particles in the suspension were in hexagonal-shaped clusters, and when this stress was exceeded, the particle arrangement was disrupted and irregular aggregations [1,2]. In another study, it is stated that the solidification mechanism is formed as a result of the hydrodynamic forces occurring between the hydroclusters. According to this study, strong hydrodynamic forces occur in the suspension under high stresses and thus the particles come into contact with each other. As a result, hydroclusters are formed as a result of the agglomeration of many particles in the suspension. This theory, called the Hydrocluster Theory, has been confirmed by many studies and is generally accepted in explaining the solidification mechanism of STFs [3,4].

Shear thickening fluids, due to this special behavior; it has been used in many areas such as armor systems [5-9], energy absorbers $[10,11]$, and vibration-damping units $[12,13]$.

Sun et al. have been observed that the application of ultrahigh molecular weight polyethylene to fabrics as STFs have a protective effect even in low-speed impact tests. After the application of STFs, it was determined that the energy absorption capacity of the fabrics increased in tests using both knife and nail tips [14]. Baharvandi et al. have been investigated the effect of STFs impregnation on Twaron para-aramid fabric on quasi-static puncture resistance. For the production of STFs, silica particles in the size range of 12 to $60 \mathrm{~nm}$ were added to PEG 200 and mixed mechanically at a mixing speed of $5700 \mathrm{rpm}$ until the suspension became homogeneous. The solid particle ratio in the suspension has been preferred as $15 \mathrm{wt} . \%, 25 \mathrm{wt} . \%$, and $35 \mathrm{wt} . \%$. It has been found that the impregnation of Twaron fabrics with STFs increases energy dissipation compared to clean fabrics [15].

$\mathrm{Xu}$ et al. have been investigated the use of STFs to increase stab resistance in the body armor. As a result of the investigations, they have seen that it is possible to obtain more protective materials with lower weight and less volume when STFs impregnated panels are used against knife impact [16].

The rheological properties of STFs can vary according to the physical conditions of solid media, liquid media, and suspension. The type and proportion of solid particles in suspension are some of the main parameters that decide the behavior of STFs. If this ratio is below a certain value, the solidification behavior of STFs may not be observed. It is known that the complex viscosity values of the suspensions increase rapidly as the solid particle ratio increases and decrease when the critical shear ratio is reached [17]. Particle size in suspension has significant effects on critical shear rate and viscosity profile. It has been reported that as the silica particle size increases, the critical shear ratio decreases, and the viscosity profile increases [17,18].

The effect of particle hardness on the rheological behavior of suspension has been studied by Kalman et al. In this research, it has been determined that the performance of hard particles was e-ISSN: 2148-2683 better when compared to producing STFs from soft and hard particles [19].

The effect of the liquid medium in the suspension on the rheological properties has been studied by many researchers. Increasing the molecular weight of polyethylene glycol used as a liquid medium also increased the viscosity of the suspension. It is known that factors such as temperature, mixing speed, and environmental conditions other than the materials that make up the suspension affect the rheological properties [18,20,21]. In the study by Gürgen, the rheological properties of STFs with $20 \mathrm{wt} . \%$ silica content have been investigated depending on the temperature, and it is evaluated that increasing the temperature decreases the suspension viscosity [22].

This research aims to determine the effect of the production method on the dispersion quality in obtaining the shear thickening fluids. In the experimental study, the production of STFs has been carried out with three different methods. The production method of STFs; made using mechanical, ultrasonic, and both mechanical and ultrasonic stirrers. With the optimization studies, both the experimental conditions for the production of STFs and the maximum rheological performance evaluation have been made. Also, the effect of shear rate operating range and the distance between parallel plates in the rheology device on complex viscosity measurements are discussed.

\section{Material and Method}

Two different fumed silica (aerosil 150, and aerosil 200 from Evonik) were used as solid particles for the production of STFs. Two different densities of polyethylene glycols (PEG 300 and PEG 400) were chosen as the liquid medium. Since shear thickening fluid-behavior may not be observed in suspensions with low solid particle concentrations, $20 \mathrm{wt} . \%$ and $25 \mathrm{wt} . \%$ solid particle ratios were preferred as in previous studies $[17,23]$. The properties determined by the manufacturer of the materials used in the production of STFs are given in Table 1 and Table 2.

Table 1. Properties of silica nanoparticles

\begin{tabular}{c|c|c}
\hline Properties & Aerosil 150 & Aerosil 200 \\
\hline Surface area $\left(\mathrm{m}^{2} / \mathrm{g}\right)$ & 150 & 200 \\
\hline Particle diameter $(\mathrm{nm})$ & 14 & 12 \\
\hline Tamped density $\left(\mathrm{kg} / \mathrm{m}^{3}\right)$ & 43 & 50 \\
\hline $\mathrm{SiO}_{2}$ content $(\%)$ & 99.8 & 99.8 \\
\hline
\end{tabular}

Table 2. Properties of polyethylene glycol

\begin{tabular}{c|c|c}
\hline Properties & PEG 300 & PEG 400 \\
\hline Molecular weight $(\mathrm{g} / \mathrm{mol})$ & 300 & 400 \\
\hline Density $\left(\mathrm{kg} / \mathrm{m}^{3}\right)$ & 1125 & 1130 \\
\hline Flash temperature $\left({ }^{\circ} \mathrm{C}\right)$ & 220 & 305 \\
\hline
\end{tabular}

In the first stage of sample production, silica particles have been dried in an oven at $150{ }^{\circ} \mathrm{C}$ for approximately 12 hours. To prepare STFs samples, polyethylene glycols and silica particles were mixed with different homogenization methods. Mechanical $(\mathrm{M})$, ultrasonic $(\mathrm{U})$, and both mechanical and ultrasonic $(\mathrm{M}+\mathrm{U})$ mixing processes were applied in the production of suspensions. Mechanical mixing was done with a high-speed mechanical mixer at $6000 \mathrm{rpm}$. The ultrasonic mixing process was carried out with SONOPULS HD 2200 model ultrasonic mixer at $20 \mathrm{kHz}$ frequency. During the mixing process, silica particles were added 
gradually to prevent aggregation, as suggested in previous studies $[17,24,25]$. Mixing was carried out in a temperature-adjustable water bath to prepare suspensions (Fig. 1). In the study, the plan to examine the effect of both the production method and the gap between the plates in the rheological measurements is given in Table 3 .

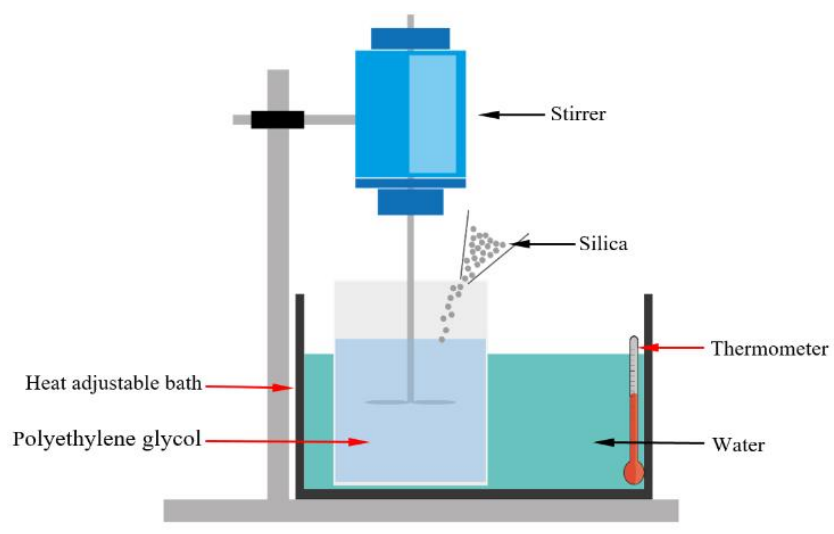

Fig. 1. Example of an image

Table 3. Sample production plan

\begin{tabular}{|c|c|c|c|}
\hline Factors & Mixture & Ratio & Method \\
\hline \multirow{3}{*}{ Mixing } & \multirow{3}{*}{$\begin{array}{c}\text { PEG } 300 \\
+ \\
\text { Aerosill } 50\end{array}$} & $20 \%$ & $M(90 \min )$ \\
\hline & & $20 \%$ & $\begin{array}{c}M+U \\
(60+15 \mathrm{~min})\end{array}$ \\
\hline & & $20 \%$ & $U(30 \mathrm{~min})$ \\
\hline \multirow{4}{*}{$\begin{array}{c}\text { Gap } \\
\text { Effect }\end{array}$} & \multirow{2}{*}{$\begin{array}{l}\text { Aerosil } 150 \\
+P E G 400\end{array}$} & \multirow{4}{*}{$25 \%$} & $M(0.2 \mathrm{~mm})$ \\
\hline & & & $M(0.3 \mathrm{~mm})$ \\
\hline & \multirow{2}{*}{$\begin{array}{l}\text { Aerosil } 200 \\
+P E G 400\end{array}$} & & $M(0.2 \mathrm{~mm})$ \\
\hline & & & $M(0.3 \mathrm{~mm})$ \\
\hline
\end{tabular}

\section{Results and Discussion}

The rheological properties of STFs have been determined using the Anton Paar MCR 102 tension-controlled rheometer shown in Fig. 2. The tests were carried out using a $25 \mathrm{~mm}$ diameter parallel plate apparatus. During the testing process, the liquids were placed in the interior between the upper and lower measuring plates. The gap between the plates was chosen as 0.2 and $0.3 \mathrm{~mm}$ and all tests were carried out at $25^{\circ} \mathrm{C}$. Rheological measurements were repeated 2 times for each sample in the range of $0-1000 \mathrm{~s}-1$ shear rate.

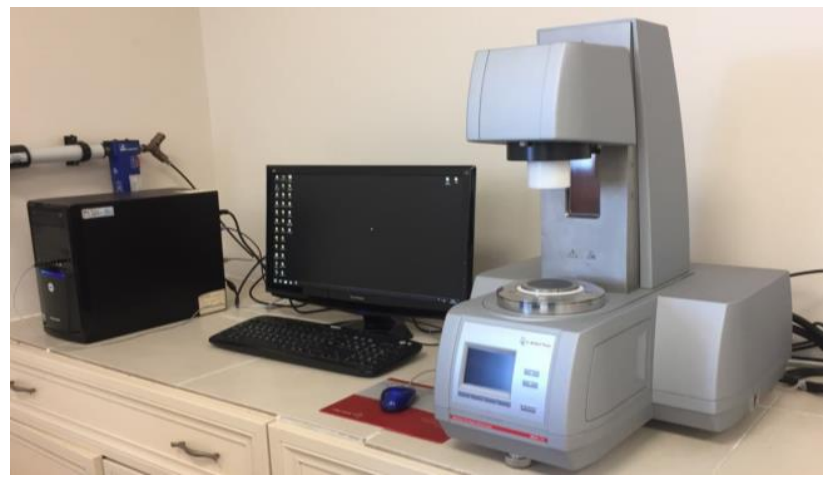

Fig. 2. Anton Paar MCR 102 Rheometer
The variation of the complex viscosity of STFs produced by different methods with shear rate is shown in Fig. 3. The best results were obtained with mechanical mixing in STFs prepared by ultrasonic $(\mathrm{U})$, mechanical $(\mathrm{M})$, both mechanical and ultrasonic $(\mathrm{M}+\mathrm{U})$ methods.

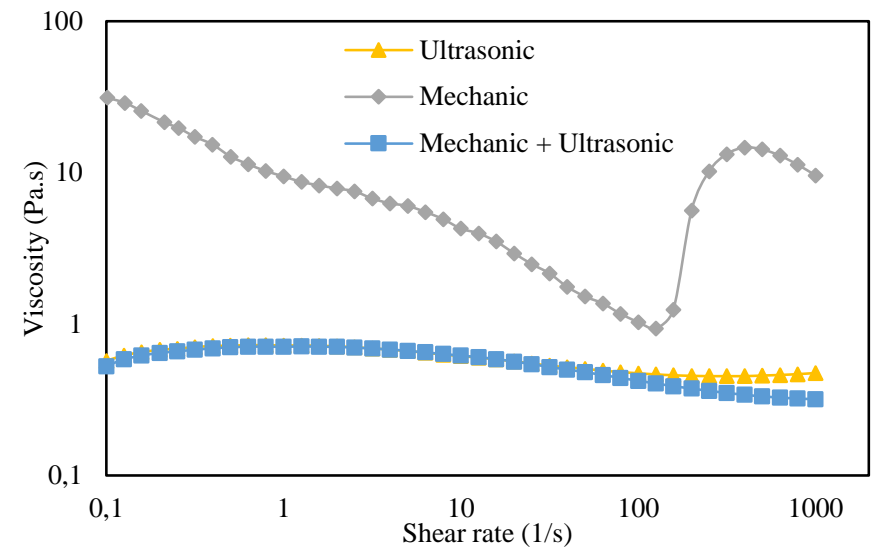

Fig. 3. Effect of production of STFs by different methods on viscosity

In Figure 4, the effect of the spacing between the parallel plates in the rheology equipment on the measurement results is compared. When the test results of STFs samples prepared in different compositions have been evaluated, it is seen that the gap between the plates did not change the rheological measurements much.

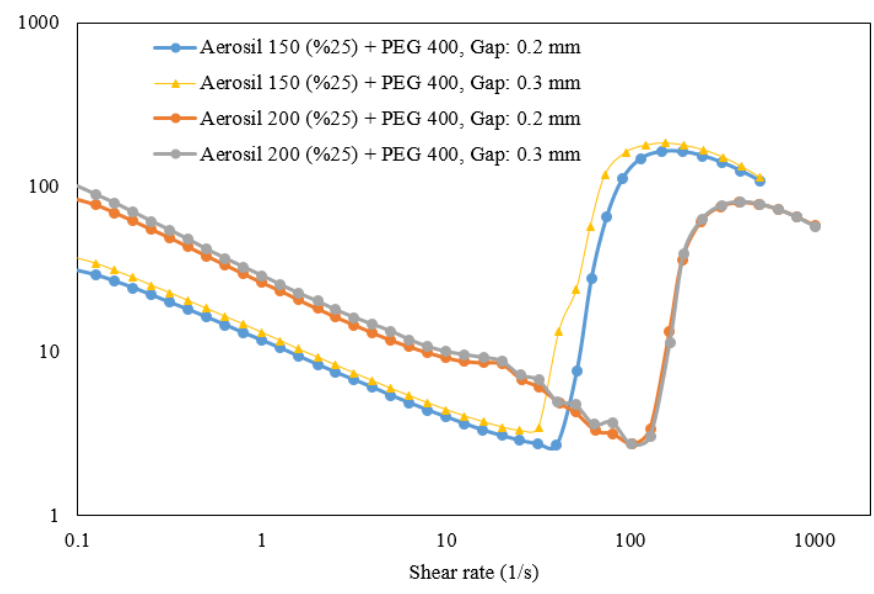

Fig. 4. Effect of spacing between parallel plates on viscosity measurements of STFs

\section{Conclusions and Recommendations}

According to the results obtained, the best performance in the STFs produced was seen in the sample prepared with $6000 \mathrm{rpm}$ mechanical stirring for 90 minutes. According to the behavior of the shear-thickening fluid, maximum stress and viscosity values were reached at high shear speed. In the rheological measurement results, it was determined that the performance of STFs increased as the molecular weight of polyethylene glycol and the particle diameter of the aerosil increased. The most ideal mixing ratio has been obtained by adding $25 \%$ by mass of solid particles (aerosil). In the measurements, it was observed that the gap change between the parallel plates did not affect the rheological results of STFs much. Besides, it is recommended to gradually add aerosil to the high-speed mechanical mixing system in the prepared mixtures. 


\section{Acknowledge}

This work was supported by Scientific Research Projects Coordination Unit of Firat University. Project number MF.19.44. The author Cenk Yanen also acknowledges the support of the Scientific and Technological Research Council of Turkey (TÜBİTAK) under Program 2211/C.

\section{References}

R.L. Hoffman, Discontinuous and Dilatant Viscosity Behavior in Concentrated Suspensions--1. Observation of a Flow Instability, Trans Soc Rheol. 1972.

R.L. Hoffman, Discontinuous and dilatant viscosity behavior in concentrated suspensions. II. Theory and experimental tests, J. Colloid Interface Sci. 1974.

W.H. Boersma, J. Laven, H.N. Stein, Viscoelastic properties of concentrated shear-thickening dispersions, J. Colloid Interface Sci. 1992.

G. Bossis, J.F. Brady, The rheology of Brownian suspensions, J. Chem. Phys. 1989.

V.A. Chatterjee, S.K. Verma, D. Bhattacharjee, I. Biswas, S. Neogi, Enhancement of energy absorption by incorporation of shear thickening fluids in 3D-mat sandwich composite panels upon ballistic impact, Compos. Struct. 225, 2019.

S. Arora, A. Majumdar, B.S. Butola, Structure induced effectiveness of shear thickening fluid for modulating impact resistance of UHMWPE fabrics, Compos. Struct. 210: 41-48, 2019.

A. Majumdar, A. Laha, D. Bhattacharjee, I. Biswas, S. Verma, Soft body armour development by silica particle based shear thickening fluid coated p-aramid fabrics, J. Text. Inst. 110: 1515-1518, 2019.

Y.H. Kim, S.K. Sathish Kumar, Y. Park, H. Kwon, C.G. Kim, High-velocity impact onto a high-frictional fabric treated with adhesive spray coating and shear thickening fluid impregnation, Compos. Part B Eng. 185, 2020.

L. Liu, Z. Yang, Z. Zhao, X. Liu, W. Chen, The influences of rheological property on the impact performance of kevlar fabrics impregnated with SiO2/PEG shear thickening fluid, Thin-Walled Struct. 151, 2020.

C. Fischer, S.A. Braun, P.E. Bourban, V. Michaud, C.J.G. Plummer, J.A.E. Månson, Dynamic properties of sandwich structures with integrated shear-thickening fluids, Smart Mater. Struct. 15: 1467-1475, 2006.

F.J. Galindo-Rosales, Complex fluids in energy dissipating systems, Appl. Sci. 2016.

S. Gürgen, M.A. Sofuoğlu, Vibration attenuation of sandwich structures filled with shear thickening fluids, Compos. Part B Eng. 186, 2020.

S. Gürgen, M.A. Sofuoğlu, Experimental investigation on vibration characteristics of shear thickening fluid filled CFRP tubes, Compos. Struct. 2019.

L.-L. Sun, D.-S. Xiong, C.-Y. Xu, Application of shear thickening fluid in ultrahigh molecular weight polyethylene fabric, J. Appl. Polym. Sci. 129: 1922-1928, 2013.

H.R. Baharvandi, P. Khaksari, M. Alebouyeh, M. Alizadeh, J. Khojasteh, N. Kordani, Investigating the quasi-static puncture resistance of p-aramid nanocomposite impregnated with the shear thickening fluid, J. Reinf. Plast. Compos. 33: 2064-2072, 2014.
Y. Xu, X. Chen, Y. Wang, Z. Yuan, Stabbing resistance of body armour panels impregnated with shear thickening fluid, Compos. Struct. 2017.

Y. Xu, Stabbing Resistance of Soft Ballistic Body Armour Impregnated with Shear Thickening Fluid, 2016.

C. Yanen, Investigation the Use of Hybrid Nanoparticle Reinforced Shear Thickening Fluid in Ballistic Applications, Firat University, 2021.

D.P. Kalman, R.L. Merrill, N.J. Wagner, E.D. Wetzel, Effect of particle hardness on the penetration behavior of fabrics intercalated with dry particles and concentrated particlefluid suspensions, ACS Appl. Mater. Interfaces. 2009.

J. Qin, G. Zhang, X. Shi, Study of a shear thickening fluid: the suspensions of monodisperse polystyrene microspheres in polyethylene glycol, J. Dispers. Sci. Technol. 38: 935-942, 2017.

H.R. Baharvandi, M. Alebooyeh, M. Alizadeh, P. Khaksari, N. Kordani, Effect of silica weight fraction on rheological and quasi-static puncture characteristics of shear thickening fluid-treated Twaron composite, J. Ind. Text. 46: 473-494, 2016.

S. Gürgen, W. Li, M.C. Kuşhan, The rheology of shear thickening fluids with various ceramic particle additives, Mater. Des. 104: 312-319, 2016.

C. Yanen, E. Aydoğmuş, M.Y. Solmaz, Determination of suitable rheological model for polyethylene glycols and silica particle mixtures, Middle East J. Sci. (MEJS). 6: 85-93, 2020.

S. Gürgen, M.C. Kuşhan, The stab resistance of fabrics impregnated with shear thickening fluids including various particle size of additives, Compos. Part A Appl. Sci. Manuf. 94: 50-60, 2017.

X.Z. Zhang, W.H. Li, X.L. Gong, The rheology of shear thickening fluid (STF) and the dynamic performance of anSTF-filled damper, Smart Mater. Struct. 17. 2008. 